\title{
Óxidos de ferro e área superficial de Latossolo subtropical sob campo e floresta nativa
}

\author{
Iron oxides and specific surface area of the subtropical Oxisol under native pasture and forest
}

\author{
Alberto Vasconcellos Inda ${ }^{I^{*}}$ Cristiano Albino Tomasi ${ }^{\mathrm{I}}$ \\ Jessica Souza de Oliveira ${ }^{\mathrm{I}}$ Jessé Rodrigo Fink ${ }^{\mathrm{I}}$
}

\begin{abstract}
As condições climáticas atuais indicam avanço da vegetação de floresta sobre os campos na região dos Campos de Cima da Serra no Rio Grande do Sul. Essa mudança na vegetação altera o conteúdo de matéria orgânica e a umidade do solo. Este estudo objetivou avaliar os óxidos de ferro pedogênicos em um Latossolo sob campo e floresta nativa e relacionar os mesmos com os teores de carbono orgânico e a área superficial específica do solo. Os teores de carbono orgânico são maiores no solo sob floresta e, possivelmente, influenciaram processos dissolutivos de óxidos de ferro cristalinos e a neoformação de tipos metaestáveis de baixa cristalinidade. $O$ incremento de $C$ orgânico no solo sob floresta elevou expressivamente a área superficial específica do solo, mascarando o efeito geralmente positivo dos óxidos de Fe sobre essa característica física.
\end{abstract}

Palavras-chave: dissolução, matéria orgânica, susceptibilidade magnética.

\section{ABSTRACT}

The current weather conditions indicate a substitution of grassland by forest vegetation in the Campos de Cima da Serra in Rio Grande do Sul, Brazil. This change in vegetation changes the contents of soil organic matter and soil moisture. This study aimed to evaluate the pedogenetic iron oxides in an Oxisol under native forest and grassland and its relationship with soil total organic carbon content and soil specific surface area. Replacing grassland with native forest resulted in an accumulation of soil organic carbon and possibly influenced dissolutive processes of crystalline iron oxides types and neoformation of metastable types of low crystallinity. In native forest soil, the increase of total organic carbon increased the soil specific surface area, masking the positive effect of iron oxides on this physical characteristic.

Key words: dissolution, organic matter, magnetic susceptibility.
Os óxidos de ferro são componentes importantes em solos tropicais e subtropicais e caracterizam-se como indicadores pedoambientais (KÄMPF \& CURI, 2000). Em pedoambientes aeróbios, estes minerais apresentam alta estabilidade e persistem no solo por longos períodos. Entretanto, incrementos no teor de matéria orgânica, aumento da umidade e da atividade microbiológica do solo favorecem os principais mecanismos de dissolução e remobilização dos óxidos de ferro no ambiente pedogênico (INDA et al., 2013).

A região dos Campos de Cima da Serra (CCS), situada na porção nordeste do Rio Grande do Sul, caracteriza-se por condições que determinam uma situação rara no mundo, de cobertura vegetal herbácea, formadora dos campos, entremeada por florestas nativas. A presença dos campos nessa região representa relicto de clima pretérito frio e seco. Com a elevação da temperatura e o aumento da umidade (4.000 anos), houve expansão da floresta nos vales, a qual se intensificou recentemente (1.100 anos) com a migração da floresta de araucária dos vales para as montanhas (OVERBECK et al., 2007). A manutenção das condições atuais (clima temperado-úmido), sugere a manutenção do desenvolvimento de vegetação florestal, com a mata invadindo as áreas de campo.

Alterações na vegetação ou na acumulação de matéria orgânica acarretam mudanças nas condições pedoambientais e na dinâmica de minerais pedogênicos (ZANELLI et al., 2007; INDA et al., 2013). O presente estudo objetivou avaliar o efeito do avanço da vegetação de floresta em áreas de campos

\footnotetext{
IDepartamento de Solos, Faculdade de Agronomia, Universidade Federal do Rio Grande do Sul (UFRGS), Av. Bento Gonçalves, 7712, 91540-000, Porto Alegre, RS, Brasil. E-mail: alberto.inda@ufrgs.br. *Autor para correspondência. Recebido 21.05.13 Aprovado 18.08.13 Devolvido pelo autor 18.11.13 CR-2013-0716.R1
} 
sobre os óxidos de ferro pedogênicos em Latossolo sob campo nativo e floresta nativa, além de sua relação com os teores de carbono orgânico total e área superficial específica.

$\mathrm{O}$ estudo foi realizado no município de André da Rocha $\left(28^{\circ} 38^{\prime} \mathrm{S}, 5^{\circ} 34^{\prime} \mathrm{O}\right)$, na região dos CCS, em altitude aproximada de $800 \mathrm{~m}$. O clima é temperado-úmido $(\mathrm{Cfb})$ com temperatura média anual de $17,6^{\circ} \mathrm{C}$ e precipitação média anual entre 1600 e $1700 \mathrm{~mm}$. O solo em relevo plano a suave ondulado foi classificado como Latossolo Vermelho Distroférrico (EMBRAPA, 2006), caracterizado pela textura argilosa e composição mineralógica caulinítica e oxídica (goethita e hematita), associada a quartzo e cristobalita; apresenta baixa saturação de bases, deficiência de $\mathrm{P}$, teores altos de matéria orgânica e níveis tóxicos de alumínio (TOMASI et al., 2012).

O solo foi avaliado sob campo nativo sem queima e sem roçada há 41 anos $(\mathrm{CN})$ e floresta nativa (FN) (HERINGER, 2000). A área de cada tratamento foi de $50 \times 50 \mathrm{~m}$, totalizando $12.500 \mathrm{~m}^{2}$. O delineamento experimental utilizado foi o inteiramente casualizado, com três repetições. Em cada ambiente, foram abertas três trincheiras e coletadas amostras de solo nas camadas de 0,00-0,025, 0,025-0,05, 0,05-0,10, 0,10$0,20,0,20-0,30$ e $0,40-0,60 \mathrm{~m}$. As amostras foram destorroadas, secas ao ar, moídas e peneiradas em malha de $2 \mathrm{~mm}$ para obtenção da fração terra fina seca ao ar (TFSA). Nesta fração, a determinação do carbono orgânico total (COT) foi realizada por combustão seca em analisador de carbono SHIMADZU TOC-V.

A fração argila foi coletada por sedimentação, segundo a Lei de Stokes, após dispersão da TFSA pelo uso do ultrassom $\left(500 \mathrm{~J} \mathrm{~mL}^{-1}\right)$. A suspensão de argila foi floculada com $\mathrm{HCl} 0,1 \mathrm{~mol}$ $\mathrm{L}^{-1}$, lavada com solução etanol/água $(1: 1)$ e seca em estufa a $50^{\circ} \mathrm{C}$. Nesta fração, o teor de ferro relativo aos óxidos de ferro pedogênicos (Fed) foi extraído por ditionito-citrato-bicarbonato de sódio (MEHRA \& JACKSON, 1960). O teor de ferro referente aos óxidos de ferro de baixa cristalinidade (Feo) foi extraído com oxalato de amônio (SCHWERTMANN, 1964). Os teores de ferro solubilizados foram determinados por espectroscopia de absorção atômica (EAA). A susceptibilidade magnética de massa específica em baixa frequência $\left(\mathrm{X}_{\mathrm{BF}}\right)$ foi determinada na fração argila em um magnetômetro Bartington MS2 acoplado a um sensor MS2B. A área superficial específica da fração argila foi estimada por adsorção de água em atmosfera de UR=20\% (QUIRK, 1955).

A determinação do desvio-padrão e a análise das relações entre os parâmetros avaliados, realizada por meio de regressões lineares, foram feitas com auxílio do programa SigmaStat 3.5.

O teor médio de COT na TFSA das camadas de solo avaliadas nos dois ambientes foi de 32,9 e $43,3 \mathrm{~g} \mathrm{~kg}^{-1}$, respectivamente, para o $\mathrm{CN}$ e FN. Os teores elevados de COT já no CN (Figura 1a) resultam do aporte de resíduos das raízes da pastagem e da lenta degradação determinada pelo clima na região dos CCS (OVERBECK et al., 2007). O incremento significativo de COT observado até a profundidade de $0,05 \mathrm{~m}$ de solo sob FN decorre da associação de plantas rasteiras e arbóreas nesse ambiente, as quais determinam maior aporte de resíduos vegetais em comparação ao $\mathrm{CN}$. Nos dois ambientes, o teor de COT do solo decresceu em profundidade.

As diferentes condições pedoambientais sob CN e FN induziram variações na mineralogia dos óxidos de ferro, também verificadas por ZANELLI et al. (2007) em florestas da Suíça e Itália, após recente substituição (20 - 50 anos) da vegetação. Os teores médios de Fe determinados na fração argila ao longo da camada superficial do solo, relativos aos óxidos de ferro pedogênicos (Fed) e aos óxidos de ferro de baixa cristalinidade (Feo), foram de 62,0 e $1,5 \mathrm{~g} \mathrm{~kg}^{-1}$ e de 53,5 e $3,8 \mathrm{~g} \mathrm{~kg}^{-1}$, respectivamente, para os ambientes $\mathrm{CN}$ e FN. Conforme constatado em outros estudos (SILVA NETO et al., 2008; LIPTZIN \& SILVER, 2009; INDA et al., 2013), a diminuição significativa da concentração de Fed no solo sob FN, em todas as camadas avaliadas (Figura 1b), pode ser consequência da dissolução de tipos cristalinos de óxidos de ferro (hematita, goethita) por reações de redução em micro sítios saturados e/ou de complexação, resultado do incremento de matéria orgânica ( $\mathrm{Fed}=62,21-$ $\left.(0,117 \times \mathrm{xCOT}) ; \quad \mathrm{R}^{2}=0,357 ; \mathrm{P}=0,040\right)$ e da maior umidade e tempo de residência da água no solo sob vegetação de floresta. A redução significativa dos valores de susceptibilidade magnética na fração argila do solo sob FN (média de $11,5 \mathrm{~m}^{3} \mathrm{~kg}^{-1} \times 10^{-7}$ ), em comparação ao solo sob CN (média de $21,1 \mathrm{~m}^{3} \mathrm{~kg}^{-1}$ $\mathrm{x} 10^{-7}$ ), confirma a dissolução de minerais pedogênicos ferrimagnéticos (maghemita) (Figura 1d). Por outro lado, o incremento significativo de Feo no solo sob FN (Figura 1c) pode estar associado à neoformação de tipos metaestáveis, como a ferrihidrita (SILVA NETO et al., 2008).

Os valores médios de área superficial específica (ASE) da TFSA ao longo da camada superficial do solo foram de 53,0 e $58,3 \mathrm{~m}^{2} \mathrm{~g}^{-1}$, respectivamente, para os ambientes $\mathrm{CN}$ e FN. O aumento significativo da ASE ao longo da camada superficial do solo (Figura 1e) mostrou uma relação positiva com o teor de COT $(\mathrm{ASE}=51,40+(0,11 \times \mathrm{xOT}$; 


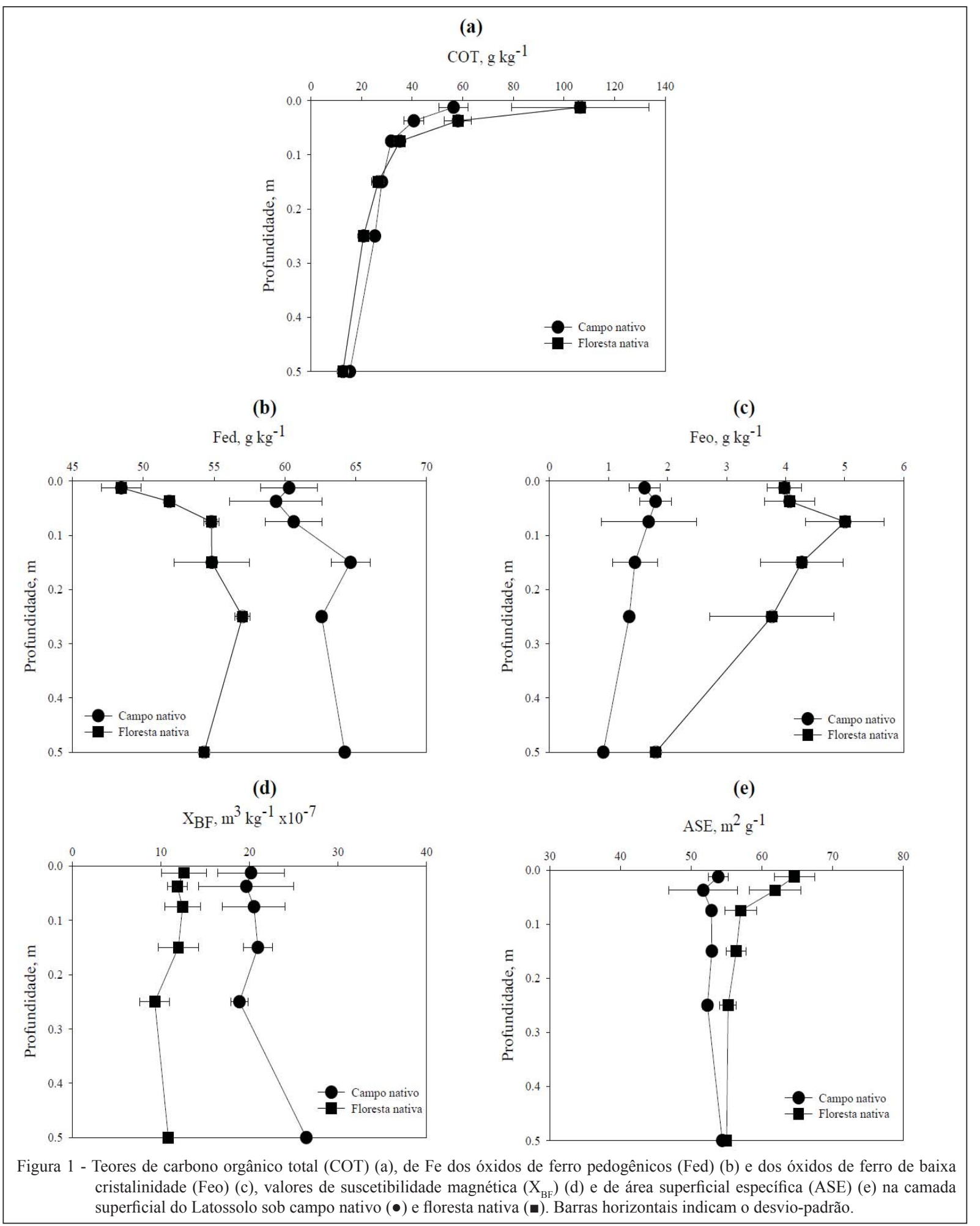

$\left.\mathrm{R}^{2}=0,546 ; \quad \mathrm{P}=0,006\right)$. Na metodologia utilizada (adsorção de água), além de não restringir a penetração de água às superfícies minerais, a MOS também participa como adsorvente de água, elevando a estimativa da ASE. Contrariando o efeito positivo normalmente verificado dos óxidos de ferro (Fed) sobre a ASE, neste estudo foi obtida uma relação inversa (ASE $\left.=93,81-(0,66 x F e d) ; \mathrm{R}^{2}=0,728 ; \mathrm{P}<0,001\right)$, 
possivelmente devido à expressiva influência da matéria orgânica sobre a ASE, a qual mascarou o efeito dos óxidos de ferro.

Considerando os resultados, na região dos Campos de Cima da Serra, o maior teor de C orgânico na camada superficial do solo sob floresta determinou mudanças pedoambientais comparativas à condição de campo nativo, as quais propiciaram reações dissolutivas dos óxidos de ferro cristalinos (hematita, goethita e maghemita) e a neoformação de tipos metaestáveis (ferrihidrita). O incremento de carbono orgânico aumentou a área superficial específica na camada superficial do solo sob condição de floresta.

\section{AGRADECIMENTOS}

Ao Conselho Nacional de Desenvolvimento Científico e Tecnológico (CNPq), pela bolsa de produtividade em pesquisa do primeiro autor e pelo suporte financeiro (Edital Universal Proc. 481694/2011-0).

\section{REFERÊNCIAS}

EMBRAPA. Centro Nacional de Pesquisa de Solos. Sistema brasileiro de classificação de solos. Rio de Janeiro: Embrapa Solos, 2006. 412p.

HERINGER, I. Efeitos do fogo por longo período e de alternativas de manejo sobre o solo e a vegetação de uma pastagem natural. 2000. 193f. Tese (Doutorado em Zootecnia) - Curso de Pós-graduação em Zootecnia, Universidade Federal do Rio Grande do Sul, RS.

INDA, A.V. et al. Iron oxides dynamics in a subtropical Brazilian Paleudult under long-term no-tillage management. Scientia Agricola, v.70, n.1, p.48-54, 2013. Disponível em: <http:// www.scielo.br/scielo.php?script $=$ sci $\operatorname{arttext\& pid=S0103-~}$ 90162013000100008\&lng=pt\&nrm=iso $>$. Acesso em: 20 maio 2013. doi:10.1590/S0103-90162013000100008.

KÄMPF, N.; CURI, N. Óxidos de ferro: Indicadores de ambientes pedogênicos. In: NOVAIS, R.F. et al. Tópicos em ciência do solo. Viçosa, MG: Sociedade Brasileira de Ciência do Solo, 2000. v.1, p.107-138
LIPTZIN, D.; SILVER, W.L. Effects of carbon additions on iron reduction and phosphorus availability in a humid tropical forest soil. Soil and Biochemistry, v.41, p.1696-1702, 2009. Disponível em: <http://www.sciencedirect.com/science/article/pii/ S0038071709002065>. Acesso em: 20 maio 2013.

MEHRA, O.P.; JACKSON, M.L. Iron oxide removal from soils and clays by a dithionite-citrate system buffered with sodium bicarbonate. Proceedings Clays and Clay Mineral Conference, v.7, p.317-327, 1960.

OVERBECK, G.E. et al. Brazil's neglected biome: the South Brazilian Campos. Perspectives in Plant Ecology, Evolution and Systematics, v.9, p.101-116, 2007. Disponível em: http:// www.sciencedirect.com/science/article/pii/S1433831907000303>. Acesso em 02 abr. 2012. doi: 10.1016/j.ppees.2007.07.005.

QUIRK, J.P. Significance of surface areas calculated from water vapour sorption isotherms by the use of the BET equation. Soil Science, v.80, n.6, p.423-430, 1955. Disponível em: <http://journals. lww.com/soilsci/Citation/1955/12000/Significance_of_Surface_ Areas_Calculated_From.1.aspx $>$. Acesso em: 02 abr. 2012.

SCHWERTMANN, U. Differenzierung der eisenoxide des bodens durch extraction mit ammoniumoxalat-lösung. Zeitscrift für Ptlanzenernàhrung und Bodenkunde, v.105, n.3, p.194-202, 1964.

SILVA NETO, L.F. da et al. Óxidos de ferro em Latossolos tropicais e subtropicais brasileiros em plantio direto. Revista Brasileira de Ciência do Solo, v.32, n.5, p.1873-1881, 2008. Disponível em: $<$ http:/www.scielo.br/scielo.php?script=sci_arttext\&pid=S0100$06832008000500008 \& \operatorname{lng}=\mathrm{pt} \& \mathrm{nrm}=\mathrm{iso}>$. Acesso em: 20 maio 2013. doi: 10.1590/S0100-06832008000500008.

TOMASI, C.A. et al. Atributos químicos e área superficial específica em Latossolo subtropical de altitude sob usos e manejos distintos. Ciência Rural, v.42, n.12, p.2172-2179, 2012. Disponível em: $<$ http://www.scielo.br/scielo.php?script=sci_arttext\&pid=S010384782012001200011\&lng=pt\&nrm=iso $>$. Acesso em: 20 maio 2013. doi:10.1590/S0103-84782012005000095.

ZANELLI, R. et al. Vegetation effects on pedogenetic forms of $\mathrm{Fe}, \mathrm{Al}$ and $\mathrm{Si}$ and on clay minerals in soils in Southern Switzerland and Northern Italy. Geoderma, v.141, p.119-129, 2007. Disponível em: <http:/www.sciencedirect.com/science/article/pii/ S0016706107001577>. Acesso em: 20 maio 2013. 